\title{
Wieder da: Nachwuchs-Stipendienprogramm „hellste Köpfe“ sucht neuen Nachwuchs
}

Den radiologischen Nachwuchs zu sichern - das ist eines der großen Ziele der Deutschen Röntgengesellschaft (DRG) und des Berufsverbands der Deutschen Radiologen (BDR). Die Initiative „Die hellsten Köpfe für die Radiologie“ ist eines der ersten großen Programme für Medizinstudierende, Famulantinnen und Famulanten sowie angehende Medizinerinnen und Mediziner im praktischen Jahr (PJ), die einmal den Deutschen Röntgenkongress - den größten deutschsprachigen Radiologie-Kongress - hautnah erleben möchten. Die Anmeldung ist ab sofort geöffnet.

Chefärztinnen und Chefärzte können als Patin oder Pate ihre eigenen hellsten Köpfe benennen. Das können Studierende, Famulanten/Famulantinnen oder PJler sein, die mithilfe des Programms einen tiefen Einblick in den Deutschen Röntgenkongress erhalten. Der Kongress vom 29. Mai bis 1. Juni 2019 ist zudem ein besonderer: Es ist der 100. Jubiläumskongress! Mehr Infos gibt es auf www.roentgenkongress.de.

\section{Melden Sie Ihre hellsten Köpfe an!}

Die hellsten Köpfe erhalten durch Ihre Patenschaft, bei der Sie pro Stipendiatin bzw. Stipendiat 250 Euro in die Zukunft Ihres Radiologie-Nachwuchses investieren, einen kostenfreien Kongressbesuch. Dazu gehören viele Kurse auf dem RöKo und ein extra zugeschnittenes Hellste-Köpfe-Programm. So können die Studierenden auch

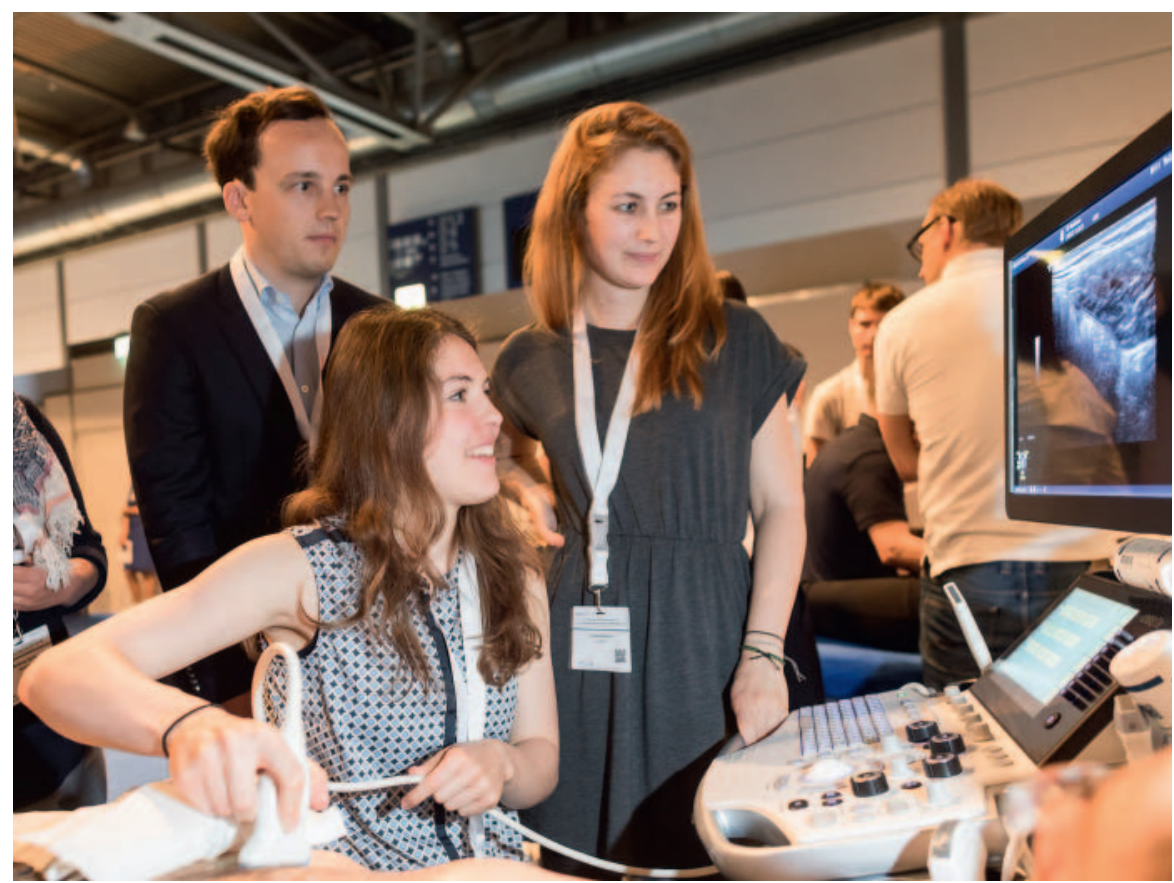

Die Teilnehmerinnen und Teilnehmer des Workshops an der Uniklinik Köln konnten MachineLearning live ausprobieren. Foto: DRG.

ihr persönliches Netzwerk, beispielsweise durch neue Kontakte im RöntgenFORUM, erweitern.

Das Hellste-Köpfe-Programm gibt es seit 2009 und hat bereits über 2000 Stipendiatinnen und Stipendiaten die Teilnahme am Deutschen Röntgenkongress ermöglicht. Damit legen die DRG und der BDR einen wichtigen Grundstein für die radiologische Nachwuchsarbeit.
Die Anmeldung Ihrer hellsten Köpfe läuft über die DRG-Geschäftsstelle. Auf www.hellste-koepfe.de finden Sie alle wichtigen Informationen. Bei Fragen wenden Sie sich gerne an Ihre HellsteKöpfe-Ansprechpartnerin bei der DRG: Anne-Katrin Hennig, 030/91 607 026, hennig@drg.de. 